\title{
CAPTAÇÃO DE ÁGUAS PLUVIAS EM PONTAL DO PARANÁ PARA OTIMIZAÇÃO DA DRENAGEM URBANA
}

\author{
Maurilio Carvalho Junior - mauriliocjr86@hotmail.com \\ Universidade Federal do Paraná
}

Fernando Armani - fernando.armani@gmail.com

Universidade Federal do Paraná 


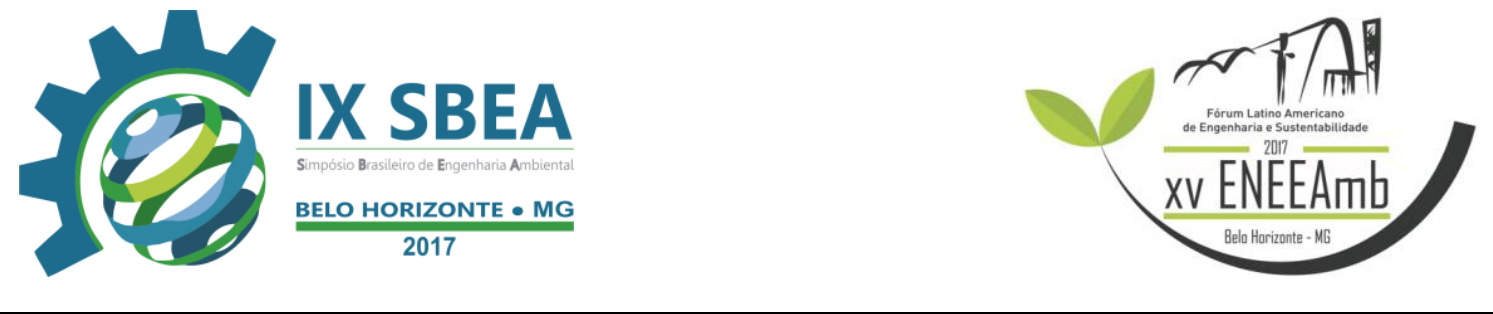

\section{RESUMO}

Este artigo apresenta a importância das medidas de controle de águas pluviais às regiões litorâneas, através de um estudo realizado na Rua Rio Grande do Norte, localizada no Balneário de Mirassol em Pontal do Paraná, a qual sofre com constantes alagamentos. A medida de controle apresentada neste trabalho é a captação de águas pluviais pelas edificações. Assim, realizou-se uma extensa revisão nas leis brasileiras que estabelecem essas medidas, das quais duas foram selecionada para avaliar o volume de água captado pelas edificações no caso hipotético em que ambas as leis estivessem sido aplicadas em 2003. Encontrou-se um volume de 2534,6 $\mathrm{m}^{3}$ de água para a lei mais restritiva, e 2320,9 $\mathrm{m}^{3}$ de água para a mais flexível dessas duas.

Palavras-Chave: Drenagem Urbana, Sistema de Captação das Águas Pluviais.

\section{INTRODUÇÃO/OBJETIVO}

O uso de água pluvial pelas edificações tem sido uma alternativa para otimizar os sistemas de drenagem urbana e para a economia do consumo dos recursos hídricos. Neste contexto, este trabalho tem como objetivo apresentar a importância do estabelecimento de medidas de controle de águas pluviais pelo poder público para as edificações do litoral do Paraná, visando a melhoria dos sistemas de drenagem urbana.

De acordo com Fendrich (2002), a captação de água da chuva por edificações é uma maneira de acabar ou reduzir o número de alagamentos, sendo uma alternativa importante para as cidades que apresentam esses problemas corriqueiramente. Nas cidades litorâneas, por exemplo, os alagamentos e enchentes são geralmente mais frequentes devido às suas condições topográficas e também porque sofrem influência do mar (SILVA et al., 2008). Especificamente na cidade de Pontal do Paraná, que está no litoral do Estado do Paraná, o regime de chuvas é bastante elevado em comparação a outras regiões do Brasil e do Paraná (SILVA, 2016). Além disso, esse litoral apresenta topografia plana e lençol freático próximo da superfície, o que dificulta o escoamento superficial das águas pluviais e a sua infiltração no solo, respectivamente. Somado a 
isso, os balneários deste litoral carecem de infraestrutura urbana, apresentando alagamentos constantes, mesmo tendo o turismo como uma das principais fontes de sua receita.

Atualmente há cerca de 24 mil habitantes em Pontal do Paraná (IBGE, 2010), mas nas temporadas o número de pessoas que frequentam este litoral eleva-se significativamente. Durante a temporada de 2015/2016 cerca de 2,5 milhões de pessoas frequentaram o litoral paranaense (G1- PR, 2016). Desta forma, o consumo de água para abastecimento público nesses períodos é consideravelmente maior, apresentando até mesmo interrupções na distribuição de água devido a sua escassez.

Em algumas cidades e Estados do Brasil, o uso de água pluvial e as medidas de controle dessas águas pelas edificações são regulamentados por leis. Tal como na cidade de Curitiba, que tem a lei 10.785/3. Essa lei estabelece que todas as novas edificações, a partir do ano de 2006, devem conter um sistema de captação de água pluvial. A lei Estadual de SP também exige a captação de água da chuva, mas somente para edificações acima de $500 \mathrm{~m}^{2}$. Já na cidade de Araraquara, foi implantada uma lei em 2015 que determina que todas as residências com área superior ou igual a $140 \mathrm{~m}^{2}$ devem possuir um sistema de captação de água da chuva. De acordo com Buono et al (2002), cerca de 133 cidades brasileiras com população igual ou superior a 200 mil habitantes possuem leis que estabelecem a implantação de sistemas de captação de água da chuva, mas apenas 19\% dos Estados do Brasil possuem leis relacionadas a este assunto.

O estabelecimento dessas leis são demasiadamente importantes, principalmente em regiões como a do litoral do Paraná, pois há dificuldades de se implantar os sistemas tradicionais de drenagem urbana devido, entre outros fatores, à topografia da região que é muito plana. Neste trabalho, estamos enfatizando a importância da implantação de medidas de controle de águas pluviais na fonte pela comparação da contribuição de águas pluviais em três cenários: o cenário atual, em que não há legislação no município determinando a implantação de medidas controle de águas pluviais pelas edificações, e os cenários hipotéticos em que teria sido implantada a lei 10.785/3 de Curitiba ou a Lei Complementar Número 865 do Município de Araraquara (SP) do ano de 2015. 


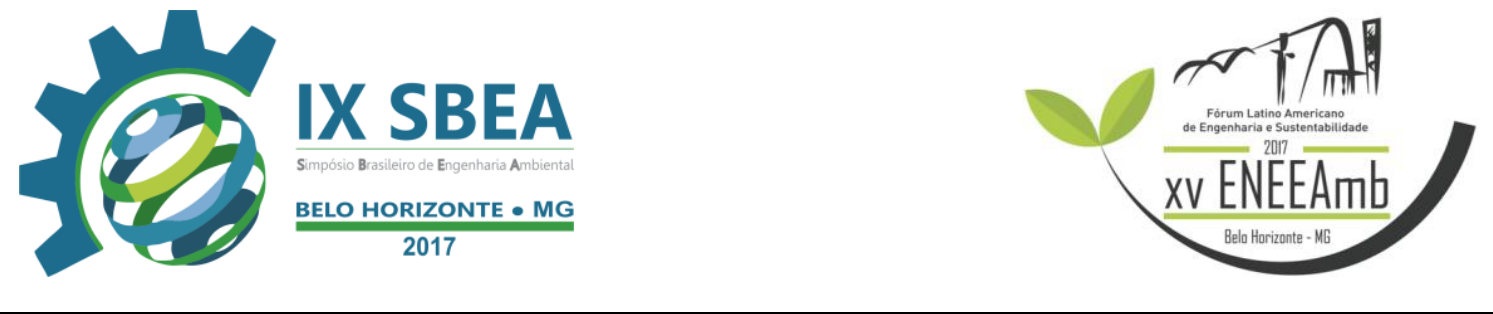

\section{METODOLOGIA}

No presente trabalho foi avaliado o impacto da aplicação da lei $10.785 / 3$ de Curitiba e da Lei Complementar Número 865 do Município de Araraquara (SP) no município de Pontal do Paraná, no caso hipotético em que ambas as leis estivessem sido implementadas no ano de 2003. Essas leis foram selecionadas com base numa revisão extensa das leis existentes no Brasil que determinam à instalação de medidas de controle de águas pluviais em edificações. Tanto quanto os presentes autores saibam, a lei brasileira mais restritiva é a lei municipal de Curitiba de número 10.785/3. Veja na tabela 1 algumas leis brasileiras que estão em vigência e que estabelecem medidas de controle de águas pluviais na fonte.

Tabela 1: Leis brasileiras que determinam a captação de águas pluviais pelas edificações

\begin{tabular}{|c|c|c|}
\hline Lei & Ano & Medida de controle na fonte. \\
\hline $\begin{array}{l}\text { Lei Municipal } 10.376 / 3 \text { de } \\
\text { Curitiba (PR) }\end{array}$ & 2006 & $\begin{array}{l}\text { Todas as novas edificações devem possuir } \\
\text { sistema de captação de água pluvial. }\end{array}$ \\
\hline $\begin{array}{l}\text { Lei Complementar Número } \\
865 \text { do Município de } \\
\text { Araraquara (SP) }\end{array}$ & 2015 & $\begin{array}{l}\text { Os proprietários de imóveis que tenham } \\
\text { construções residenciais ou comerciais, } \\
\text { com área igual ou superior } 140 \mathrm{~m}^{2} \text { devem } \\
\text { possuir sistema de captação de água } \\
\text { pluvial. }\end{array}$ \\
\hline $\begin{array}{l}\text { Lei Estadual 12526/07 de São } \\
\text { Paulo }\end{array}$ & 2007 & $\begin{array}{l}\text { Todas as edificações com área superior a } \\
500 \mathrm{~m}^{2} \text { devem possuir sistema de } \\
\text { captação de água pluvial. }\end{array}$ \\
\hline $\begin{array}{l}\text { Lei Municipal } 9.285 \text { de } \\
\text { Londrina (PR) }\end{array}$ & 2009 & $\begin{array}{l}\text { A captação da água de chuva é obrigatória } \\
\text { em todas as edificações com área igual ou } \\
\text { superior a } 200 \mathrm{~m}^{2} \text {. }\end{array}$ \\
\hline Lei Estadual 18.730 do Paraná & 2016 & Os lava-rápidos, lava-car, postos de \\
\hline
\end{tabular}




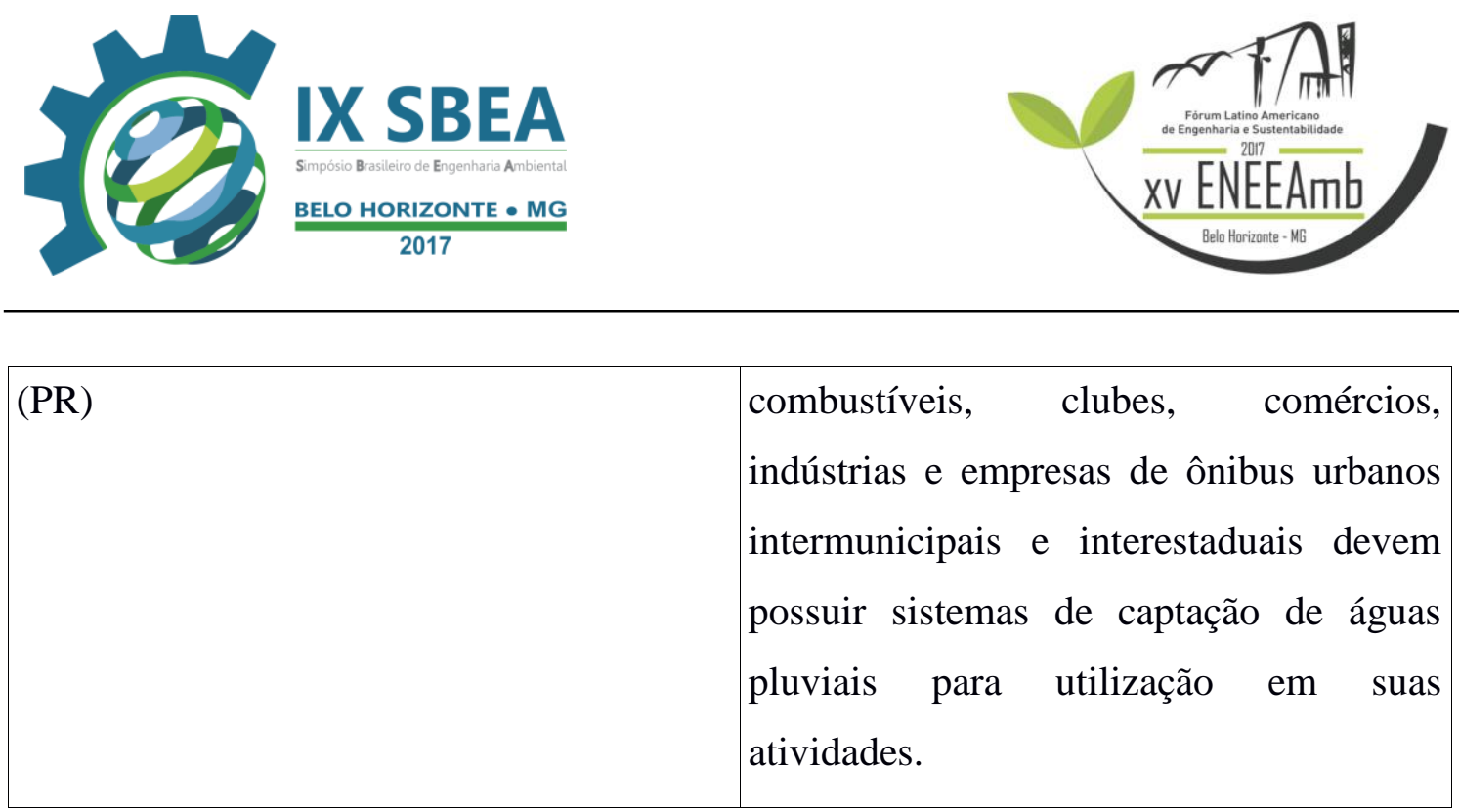

A avaliação da eficiência das medidas de controle estabelecidas pelas leis mencionadas foi realizada na rua Rio Grande do Norte do Balneário Mirassol. Esta rua é bastante semelhante às ruas paralelas a ela, onde sua inclinação é nula em quase toda a sua extensão.

Neste trabalho, considerou-se como novas áreas edificadas, as áreas das edificações presentes no ano de 2016 que não existiam no ano de 2003. Na figura 1 estão duas imagens do Google Earth, uma do ano de 2003 e outra do ano de 2016. Nota-se que a rua está mais urbanizada em 2016, onde se encontra pavimentada por blockets em boa parte de sua extensão. Em 2003 as águas pluviais que incidiam sobre esta área infiltravam no solo, mas atualmente esta área destina suas águas pluviais à rua Rio Grande do Norte.
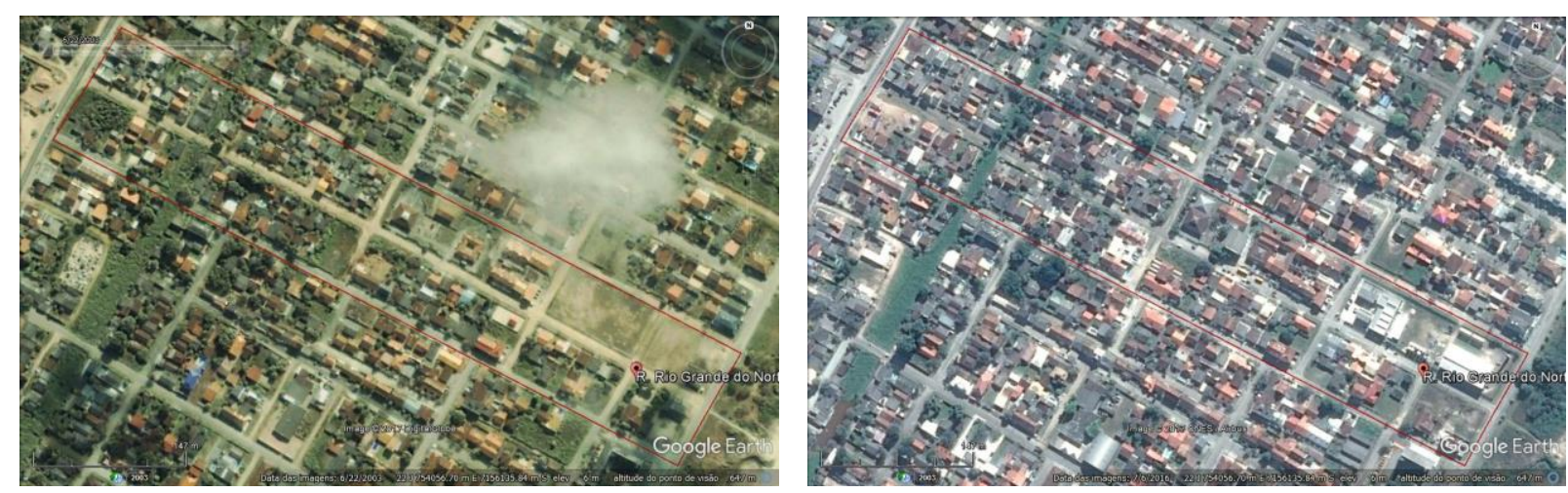

Figura 1: Na figura destaca-se a Rua Rio Grande do Norte no ano de 2003 e 2016. 


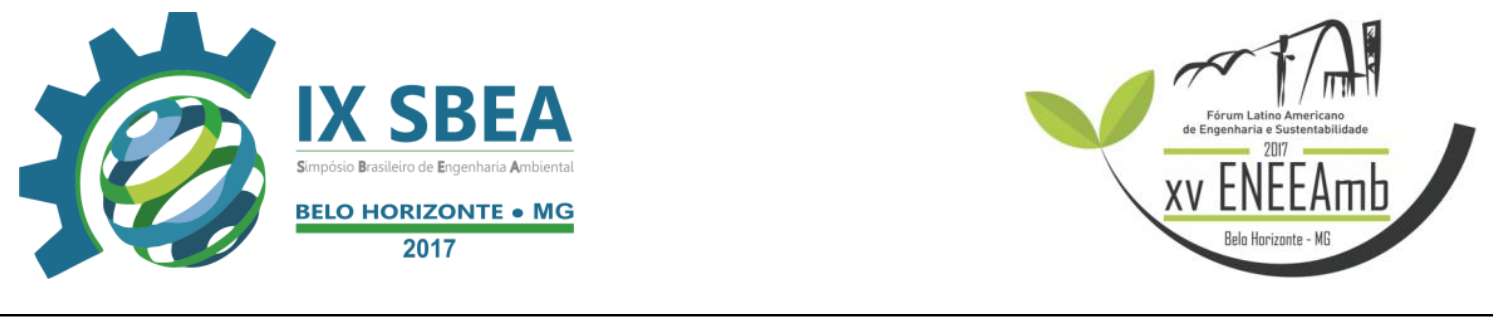

Na figura 2 está a precipitação acumulada mensal dos primeiros meses de 2017 na região. Os dados foram obtidos no site do INMET, e são da estação meteorológica automática que está localizada na Ilha do Mel (PR).

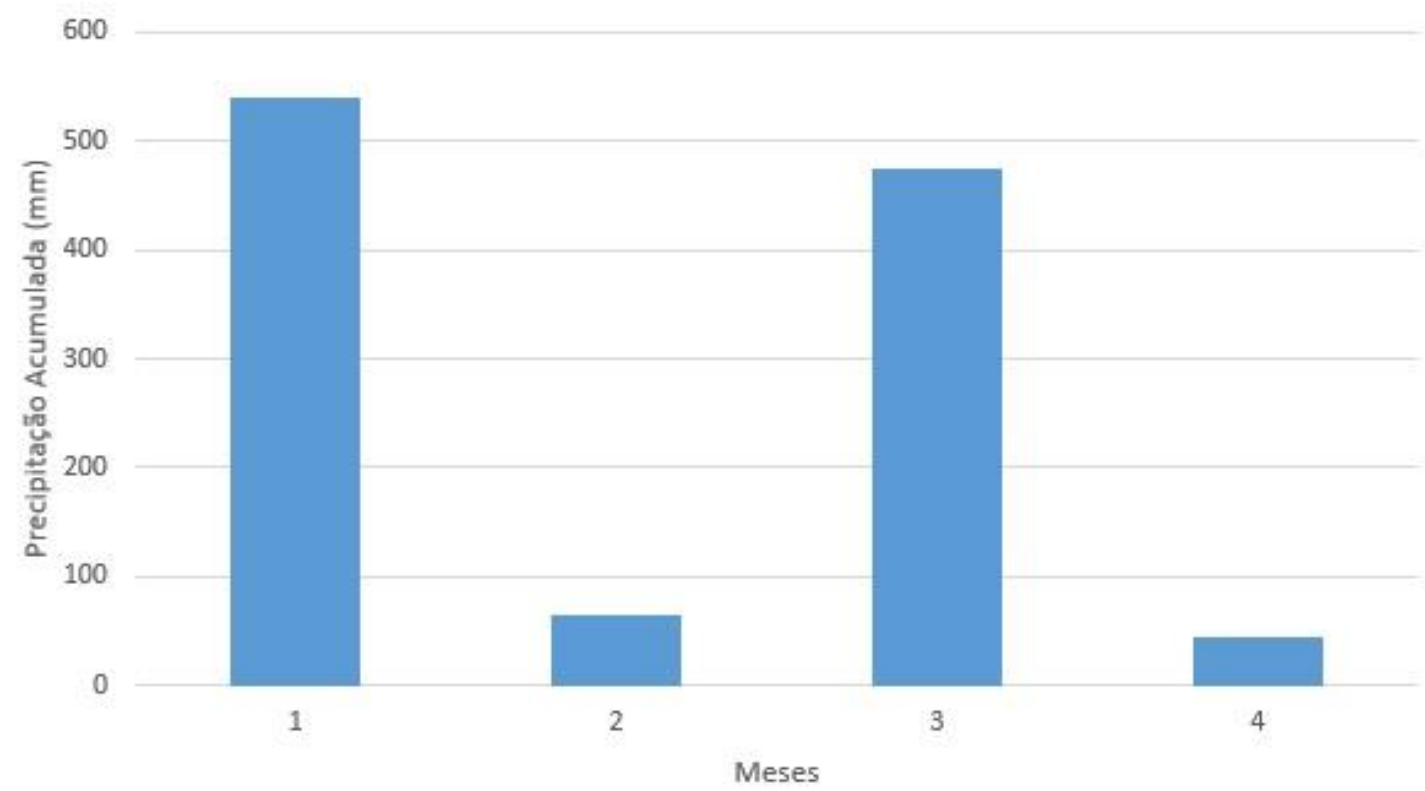

Figura 2: Precipitação acumulada mensal dos primeiros meses de 2016 (Fonte: Estação automática INMET localizada na Ilha do Mel).

Nota-se na figura 2, que entre os meses apresentados, o mês de Janeiro foi o que mais choveu. Este mês é um dos meses com maior quantidade de turistas frequentando a região, assim como é de se esperar para uma região litorânea do Brasil.

$\mathrm{O}$ volume de água pluvial (V) destinado a rua pelas novas edificações foi obtido para todos os meses apresentados na figura 2, com a equação:

$$
V=\sum_{i=1}^{N} A_{i} P
$$

em que $N$ é a quantidade das novas edificações registradas em 2016 que não existiam em 2003, $A_{i}$ é a área de cada um desses novos edifícios e $P$ é a precipitação acumulada que está na figura 2.

\section{RESULTADOS}



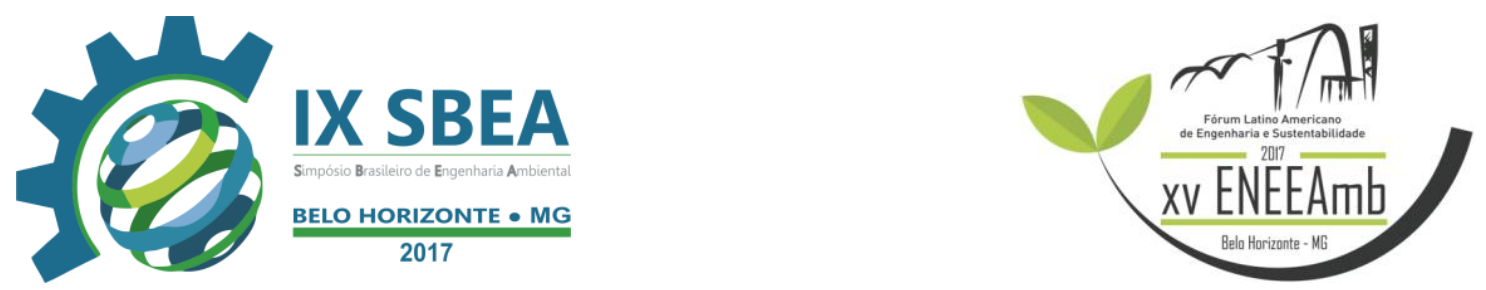

Conforme se pode observar na figura 1, esta rua está consideravelmente mais urbanizada atualmente. De 2003 a 2016 houve um aumento de $2253 \mathrm{~m}^{2}$ de áreas edificadas nesta rua (Cenário 1) e $2063 \mathrm{~m}^{2}$ de áreas maiores que $140 \mathrm{~m}^{2}$ (Cenário 2). Na figura 3 estão demarcadas as áreas contabilizadas neste estudo.

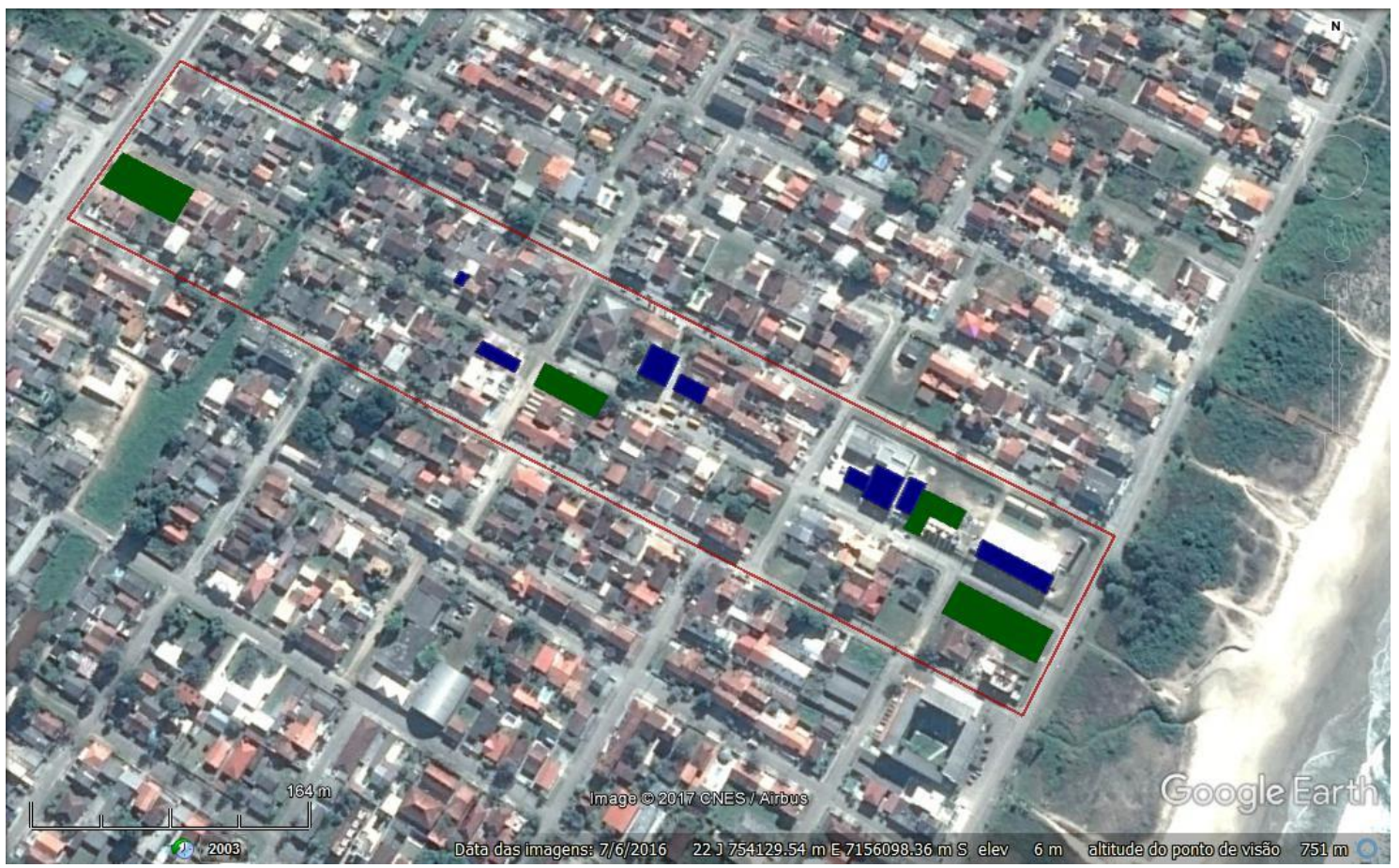

Figura 3: Imagem do ano de 2016 da Rua Rio Grande do Norte obtida no Google Earth. As áreas pintadas na cor azul são as áreas edificadas em 2016 que não existiam em 2003. Em verde estão as áreas não edificadas em 2016.

Tabela 2: Volume de água pluvial captado pela edificações em cada mês para o cenário 1 e 2 .

\begin{tabular}{|l|c|c|c|c|}
\hline & \multicolumn{4}{|c|}{ Volume de água $\left(\mathrm{m}^{3}\right)$ nos meses: } \\
\hline & 1 & 2 & 3 & 4 \\
\hline $\begin{array}{l}\text { Volume de água pluvial captado por } \\
\text { todas as novas edificações }\end{array}$ & 1216,6 & 146,4 & 1070,2 & 101,4 \\
\hline
\end{tabular}




\begin{tabular}{|l|l|l|l|l|}
\hline $\begin{array}{l}\text { Volume de água pluvial captado pelas } \\
\text { novas edificações com área maior do } \\
\text { que } 140 \mathrm{~m}^{2}\end{array}$ & 1114,0 & 134,1 & 980,0 & 92,8 \\
\hline $\begin{array}{l}\text { Volume de água pluvial que incide } \\
\text { sobre as áreas que não estão edificadas } \\
\text { em } 2016\end{array}$ & 2211,10 & 266,15 & 1944.94 & 184.25 \\
\hline
\end{tabular}

O volume de água que poderia ter sido captado por todas as novas edificações nesses quatro meses é de 2534,6 $\mathrm{m}^{3}$, enquanto que o volume de água que poderia ter sido captado pelas edificações maiores do que $140 \mathrm{~m}^{2}$ é de $2320,9 \mathrm{~m}^{3}$. Considerando que o mês de janeiro é um dos meses com maior quantidade de turistas frequentando a região, apenas neste mês, teria havido uma redução de $1216,6 \mathrm{~m}^{3}$ no consumo de água de abastecimento público para o cenário 1 e $1114 \mathrm{~m}^{3}$ no consumo de água de abastecimento público para o cenário 2 .

As áreas destacadas na cor verde indicam os terrenos que ainda não foram edificados. Atualmente as águas pluviais que incidem nestes terrenos permanecem no local, e infiltram no solo. No futuro, as edificações que se estabelecerão nestes locais também destinarão as águas pluviais à rua Rio Grande do Norte. Portanto, o volume de água que será destinado a esta rua num mês cuja precipitação foi semelhante a do mês de janeiro de 2017 é de $2211,10 \mathrm{~m}^{3}$.

\section{CONCLUSÃO}

Os sistemas de microdrenagem urbana são geralmente projetados com base no método racional (Governo do Estado do Paraná, 2002), mas na rua apresentada neste estudo, este método não se aplica porque esta rua é plana em quase toda a sua extensão. Desta forma, há dificuldades em se construir os sistemas tradicionais de microdrenagem.

Conforme se demonstrou na seção anterior, as medidas de controle de água pluvial na fonte são de fundamental importância no litoral do Paraná, para atenuar ou 
extinguir os corriqueiros alagamentos observados. Considerando o fato de que na rua se formam diversas zonas de alagamento, e de que no futuro haverá um aumento significativo no volume de água destinada a esta rua quando as áreas verdes estiverem edificadas.

As pluviais podem ser utilizadas pela população para diversos fins, minimizando tanto os alagamentos quanto o consumo das águas de abastecimento público, em volumes semelhantes aos apresentados na seção anterior.

\section{REFERÊNCIAS BIBLIOGRÁFICAS}

SILVA, E. S. Variedade da Precipitação Pluviométrica Nas Regiões Sudeste e Sul do Brasil.2006. 188 f. Tese (Doutorado em Agronomia) - Faculdade de Ciências Agronômicas da UNESP.São Paulo. 2016.

FENDRICH, R. Aplicabilidade do armazenamento, utilização e infiltração das águas pluviais na drenagem urbana. $144 \mathrm{f}$. Tese (Doutorado em Geologia Ambiental) - Setor Ciências da Terra, Universidade Federal do Paraná. 2002.

BUONO. L. N.; CONTANZI, R. N.; PERALTA, A. H. Políticas públicas para aproveitamento de águas pluviais, Universidade Tecnológica Federal do Paraná, Londrina - PR. v. 1, 1p. 2002.

INSTITUTO BRASILEIRO DE GEOGRAFIA E ESTATISTICA. População de Pontal do Paraná. Disponível em: <http://cidades.ibge.gov.br/xtras/perfil.php?codmun=411995> Acesso em: 10 maio 2017.

FREIRE, C. Milhares comemoram a virada de ano nas praias do litoral paranaense. Disponível em: <http://g1.globo.com/pr/parana/feriasverao/2017/noticia/2017/01/milharescomemoram-virada-de-ano-nas-praiasdo-litoral-paranaense.html>

SILVA, T. C.; CARVALHO, M. B. M.; GADELHA, C. L. M.; RAIMUNDO, W. S. J. Diagnóstico e Hierarquização de Problemas de Drenagem Urbana da Zona Costeira Sul do Estado do Paraíba, Eng. sanit. ambient, Vol.13, $\mathrm{N}^{\circ}$ 2, abr/jun 2008, 144152Eng.

GOVERNO DO ESTADO DO PARANÁ. Manual de Drenagem Urbana: Regiões Metropolitanas de Curitiba. Curitiba, 2002. 150 p. 
BRASIL, IBGE. CENSO DEMOGRÁFICO, 2010. Disponível em: <www.ibge.gov.br>. Acesso em: 15 mar. 2017. 